\title{
In-Service Astronomy Education of Teachers
}

\author{
Michèle Gerbaldi \\ Université de Paris Sud XI and Institut d'Astrophysique de Paris, 98 \\ bis Bd Arago, 75014 Paris - France \\ E-mail: gerbaldi@iap.fr
}

\begin{abstract}
Astronomy education of school teachers is reviewed in the context of in-service training when astronomy is part of the curriculum, or not. Methods and results are presented based on experiences of teacher training during 25 years, in France.
\end{abstract}

\section{Introduction}

Whatever the country is, in general few teachers have been educated in astronomy during their curriculum at the university or at the training colleges, astronomy being an optional subject. So in-service training of the school teachers is necessary either because astronomy has been introduced in the school curriculum or because the teachers themselves are introducing some touch of astronomy in their lessons.

Examples of in-service training have been taken from the French educational system because it is applied to a large body of teachers, the French curriculum being a national one and also because in-service training in astronomy started 25 years ago through the non-profit association CLEA (Comité de Liaison Enseignants Astronomes, Teacher-Astronomers Joint Committee; http://www.acnice.fr/clea/)

Such training is done in two directions: one which concerns the background in astronomy-astrophysics and the other which gives to the teachers the possibility to develop pedagogical resources, not forgetting that the school teachers are also active in peri-scholar activities: club, educational projects.

\section{Context}

Based on our experience, we can testify that even with no astronomy in the curriculum, it is extremely fecund to develop an in-service training, with a small nucleus of dedicated teachers with the following objectives:

- to create a network of trained teachers becoming resource persons

- to create links between the interested teachers (newsletter, web pages)

- to exchange teaching material

- to create astronomers-teachers partnerships.

Such in-service training will be of great help to give a strong push to introduce astronomy in the school curriculum due to the fact that there is already 
an experience of teacher-training and also because teaching astronomy has been tested by some teachers.

When astronomy is part of the curriculum numerous teachers have to be trained and it is at this point that the resource persons trained previously have to play an important rôle besides the professional astronomers who are too few in any case. Moreover the resource persons can act locally in their teaching district by personal contacts with their colleagues and informal meetings.

\section{Methods}

Various teacher training modes have been developed each acting on different aspects of the training. Some are directed to the long-term training aiming to give a full autonomy to the teachers, some are much more selective concerning the subjects introduced and are efficient on the short-term or only one one aspect of the curriculum.

The various modes of teacher training which are mainly used are:

- summer school: about 8 days

- 3-days, 1-day training session during the school year, organized locally

- distance learning courses, granted or not by a diploma.

- self study (Internet, CD-ROM, ...)

\section{Results and Conclusion}

Any method used in the education of teachers will be effective only if astronomers have developed long-term relationships with school teachers that nurture both teachers' astronomy knowledge and their pedagogical knowledge. The best way to achieve this goal is the summer schools from which a network of school teachers, trained in astronomy not only on theory but also having a large experience of various activities in their classroom, will be created. These resource persons will then be able to act locally.

Internet and/or CD-ROM do not provide a full alternative. They may be used for the resources or to disseminate practical exercises developed or to establish some tutorials but not to acquire fundamental knowledge.

But nothing will be achieved if there are no astronomers ready to provide the "gift of their time" to such goal of school teachers training in Astronomy. 